\title{
Expression profiling of esophageal squamous cell carcinoma patients treated with definitive chemoradiotherapy: Clinical implications
}

\author{
AKIO ASHIDA ${ }^{1}$, NARIKAZU BOKU ${ }^{2}$, KAZUHIKO AOYAGI $^{1}$, HIROSHI SATO ${ }^{1}$, YASUHIRO TSUBOSA ${ }^{1}$, \\ KEIKO MINASHI ${ }^{2}$, MANABU MUTO ${ }^{2}$, ATSUSHI OHTSU ${ }^{2}$, ATSUSHI OCHIAI ${ }^{3}$, \\ TERUHIKO YOSHIDA ${ }^{1}$, SHIGEAKI YOSHIDA ${ }^{2}$ and HIROKI SASAKI ${ }^{1}$ \\ ${ }^{1}$ Genetics Division, National Cancer Center Research Institute, 1-1 Tsukiji 5-chome, Chuo-ku, Tokyo 104-0045; \\ ${ }^{2}$ GI Oncology Division, and ${ }^{3}$ Pathology Division, Hospital East, National Cancer Center, Kashiwa-shi, Chiba 277-8577, Japan
}

Received December 12, 2005; Accepted February 8, 2006

\begin{abstract}
In esophageal squamous cell carcinoma (ESCC), chemoradiotherapy (CRT) has a curative potential even in cases of locally advanced carcinoma. However, only about half of the patients benefit from CRT, and an accurate prediction of sensitivity to CRT is eagerly awaited. Using microarrays, we analyzed gene-expression patterns of pretreatment biopsy specimens from 33 patients with CRT alone including longterm survivors, more than 3 years (14 cases) and short-term survivors, less than 1 year ( 11 cases). The expression patterns of about 12,600 genes were used to identify genes correlated with survival terms. Fifty-seven genes correlating with shortterm survival and 120 genes with long-term survival were identified. The genes involved in the immune response were characteristically upregulated in the long-term survivors, and an immunohistochemical staining confirmed an increased CD8positive $\mathrm{T}$ cell number in the long-term survivors over that in the short-term survivors. In the short-term survivors, on the other hand, increased expression of the genes involved in drug resistance was observed. Our gene list should contribute to the elucidation of the mechanisms of CRT response and contains useful markers for predicting the prognosis of individual ESCC patients treated with CRT alone.
\end{abstract}

\section{Introduction}

Esophageal cancer in East Asian countries including Japan and China, and in some parts of Europe consists mainly of squamous cell carcinomas located mostly in the thoracic esophagus, while adenocarcinoma in the distal part of the

Correspondence to: Dr H. Sasaki, Genetics Division, National Cancer Center Research Institute, 1-1 Tsukiji 5-chome, Chuo-ku, Tokyo 104-0045, Japan

E-mail: hksasaki@gan2.res.ncc.go.jp

Key words: microarray, esophageal cancer, chemoradiotherapy, prognosis esophagus has increasingly become the major pathological type found in Europe and North America. Overall, esophageal squamous cell carcinoma (ESCC) is the sixth most frequent cancer in the world, and is a highly virulent disease. Although surgery is the standard therapy for locally confined ESCC, results of surgery alone remain poor, with 5-year survival rates of 6-24\% in Western countries (1). Recent improvement in surgical results following radical node dissection has been reported at some Japanese institutions, with 5-year survival rates of $31-55 \%(2,3)$. In a Japanese prospective randomized study that compared surgery alone with surgery followed by adjuvant chemotherapy, the group that received surgery with radical dissection alone showed a 5-year survival rate of $45 \%$, although the study did not show a survival advantage over treatment with adjuvant chemotherapy (4). The success of radical surgery led many Japanese surgeons to extend the indications of surgery to locally advanced carcinoma. On the other hand, a combination of 5-fluorouracil (5-FU) and cisplatin (CDDP) has become a standard world regimen, not only because of its clinical outcome, but also because of the synergism between the two agents and their radiosensitizing effects (5-7). Recent studies clearly indicated that definitive chemoradiotherapy (CRT) seemed to have a curative potential even in cases of locally advanced carcinoma (8), although the treatment may be associated with significant toxicity (9). The reported 5 -year survival rate is $27 \%$ or $29 \%(9,10)$. Despite recent progress in the molecular genetics of ESCC, little is known about the mechanisms of sensitivity to CRT, and a prediction of the outcome of CRT by clinicopathological terms still remains very difficult. We conducted gene expression profiling using an oligonucleotide microarray of pretreatment biopsy samples from 33 ESCC patients treated with CRT alone. The purpose of the study was to explore the underlying mechanisms of CRT responses and to contribute to the development of the markers, which aid to select the best therapeutic modality prior to the initiation of therapy.

\section{Materials and methods}

RNA isolation from biopsy specimens. Patients received protracted infusion of $5-\mathrm{FU} 400 \mathrm{mg} / \mathrm{m}^{2} / 24 \mathrm{~h}$ on days $1-5$ and 
8-12, 2-h infusion of CDDP $40 \mathrm{mg} / \mathrm{m}^{2}$ on days 1 and 8 , and concurrent radiation therapy at a dose of $30 \mathrm{~Gy}$ in 15 fractions over 3 weeks. Filgrastim was prophylactically administered to all patients. This schedule was repeated twice every 5 weeks, for a total radiation dose of $60 \mathrm{~Gy}$, followed by two courses of 5 -FU ( $800 \mathrm{mg} / \mathrm{m}^{2} / 24 \mathrm{~h}$ for 5 days) and CDDP $\left(80 \mathrm{mg} / \mathrm{m}^{2}\right.$ on day 1). Biopsy samples, which were obtained from patients before CRT, were immediately frozen at $-80^{\circ} \mathrm{C}$ until use. The samples were homogenized in Isogen lysis buffer (Nippon Gene Co., Ltd., Toyama, Japan) at room temperature, extracted with chloroform, and precipitated with $20 \mu \mathrm{g}$ glycogen in isopropanol. The RNA pellet was resuspended in RNase-free water, and treated with RNase-free DNase I in the presence of RNase inhibitor followed by phenol extraction and precipitation in isopropanol. The pellet was resuspended in $15 \mu 1$ of RNasefree water; one-third of the total RNA from each sample was used for quality analysis of RNA by RNA LabChip (Caliper Technologies Corp., CA), and an appropriate amount from the remaining two-thirds was used for oligonucleotide microarray analysis. This study with biopsy specimens was approved by our institutional review boards.

Microarray analysis. We used human U95A oligonucleotide probe arrays (Affymetrix, Santa Clara, CA) for analysis of mRNA expression levels corresponding to 12,600 transcripts. The procedures were conducted according to the supplier protocols, and are thus described briefly. Each $5 \mu \mathrm{g}$ of total RNA was used to generate a cRNA probe. Ten microgram of fragmented cRNA was hybridized to the microarrays in $200 \mu \mathrm{l}$ of a hybridization cocktail at $37^{\circ} \mathrm{C}$ for $16 \mathrm{~h}$ in a rotisserie oven set at $60 \mathrm{rpm}$. The arrays were then washed with a low stringent wash buffer (6X SSPE) at $25^{\circ} \mathrm{C}$, followed by stringent wash buffer [100 mM MES (pH 6.7), $0.1 \mathrm{M} \mathrm{NaCl}$, and $0.01 \%$ Tween-20] at $50^{\circ} \mathrm{C}$, stained with streptavidin phycoerythrin (Molecular Probes), washed again with 6X SSPE, stained with biotinylated anti-streptavidin IgG, followed by a second staining with streptavidin phycoerythrin and a third wash with 6X SSPE. The arrays were scanned using a GeneArray scanner (Affymetrix) at $3-\mu \mathrm{m}$ resolution, and quantitatively the canned image analyzed with computer software Microarray Suite 4.0 (Affymetrix). For normalization of the data to compare mRNA expression levels among the samples, we unified 1000 as an average of $\mathrm{AD}$ scores corresponding to signal intensities of all probe sets in each sample. We selected genes whose expression levels were higher than an average of signal intensity in one group (14 long-term survivors or 11 short-term survivors) plus its standard deviation (SD) in more than $60 \%$ of another group. The two-dimensional hierarchical clustering analysis of the 177 selected genes differentially expressed in longand short-term survivors was performed by the Cluster and Treeview programs (11).

RNA slot blot analysis. To verify differences in expression indicated by microarray analysis, we performed slot blot analysis of cRNAs produced from total RNA extracted from 14 long-term survivors and 12 short-term survivors. A SuperScript Choice System (Invitrogen Corp., CA) was used for cDNA synthesis prior to generating cRNA. A MEGAscript in vitro Transcription Kit (Ambion Inc., TX) was used for cRNA production by in vitro transcription using T7 RNA polymerase. Each $0.5 \mu \mathrm{g}$ cRNA was denatured and blotted to a NitroPlus membrane (Micron Separations, Inc.). The filter was hybridized with radiolabeled probes. Hybridization was carried out in $50 \%$ formamide, $5 \mathrm{X}$ standard saline citrate (SSC) (1X standard saline citrate $=0.15 \mathrm{M} \mathrm{NaCl}, 0.015 \mathrm{M}$ sodium citrate), $5 \mathrm{X}$ Denhardt's solution, $5 \mathrm{mM}$ EDTA, $0.1 \%$ sodium dodecyl sulfate (SDS), 10\% dextran sulfate, and 100 $\mu \mathrm{g} / \mathrm{ml}$ denatured salmon sperm DNA at $42^{\circ} \mathrm{C}$ for $16 \mathrm{~h}$. The filter was washed twice in $0.1 \mathrm{X} \mathrm{SSC}$ and $0.1 \% \mathrm{SDS}$ at room temperature for $10 \mathrm{~min}$ each and then washed at $65^{\circ} \mathrm{C}$ for 30 min, and exposed to Kodak XAR film at $-80^{\circ} \mathrm{C}$.

Immunohistochemical analysis. Biopsy specimens were embedded in paraffin, sectioned, and treated with phosphatebuffered saline (PBS). The specimen was then treated with a blocking reagent containing $10 \%$ goat serum and incubated with an anti-CD8 antibody in PBS also containing 3\% goat serum. After incubation with the secondary antibody, a streptavidin-peroxidase solution was applied to the specimen followed by a development solution containing diaminobenzidine.

\section{Results}

Classification of ESCC patients who received CRT alone and microarray analysis. The clinicopathological characteristics of 33 esophageal carcinoma patients who received CRT alone are summarized in Table I. All cases were diagnosed as squamous cell carcinoma, and all patients were treated according to the same protocol as described in Materials and methods. Twenty-five of the 33 patients were classified into two groups on the basis of the duration of survival: long-term survivors, more than 3 years (14 cases, A-1-1 to A-1-14); short-term survivors, less than 1 year (11 cases, D-1-1 to D-1-11). The two groups showed no significant differences with respect to clinicopathological features. Of the remaining 8 patients, 6 (A-2-1 to A-2-4, D-2-1, and D-2-3) survived for 2-3 years until the end of the follow-up period, and 2 patients (D-2-2 and D-2-4) survived for 1-2 years. Approximately 10-30 $\mu \mathrm{g}$ of total RNA was isolated from each biopsy sample of these 33 ESCC patients, and all RNA samples were confirmed to be of good quality by visualization of ribosomal RNAs using the capillary electrophoresis method as described in Materials and methods and considered sufficient for microarray analysis. The 33 RNA samples were converted to cRNA, labeled by biotin and hybridized to Affymetrix Human Genome U95Av2 Array according to the protocol recommended by the manufacturer (Affymetrix, CA, USA). The array analyzed mRNA expression levels corresponding to 12,600 transcripts. First, we conducted an unsupervised clustering analysis using the 316 genes expressed (i.e., gave 'Presence' call by data analysis) in all the 33 samples. Three patient clusters appeared (Fig. 1). Cluster 1 ( 7 cases) consisted of 5 long-term survivors (A-1-1, A-1-7, A-1-9, A-1-11, and A-1-13), and 6 of the 7 cases $(86 \%)$ in this cluster survived for more than 2 years. Cluster 2 (15 cases) consisted of 9 short-term survivors (D-1-1 to D-1-5, and D-1-7 to D-1-10), and $73 \%$ of the cases of this cluster (11 of 15) survived for less than 2 years. Cluster 3 (11 cases) consisted of 6 long-term survivors (A-1-2, A-1-5, A-1-6, A$1-10, A-1-11$, and A-1-14), and 10 of the 11 cases (91\%) of 
Table I. Clinical outcome and disease stage of 33 patients.

\begin{tabular}{|c|c|c|c|c|c|c|c|c|}
\hline No. & Age & Sex & $\mathrm{T}$ & $\mathrm{N}$ & $\mathrm{M}$ & TNM stage & $\mathrm{CR}^{\mathrm{a}}$ & Outcome $^{\mathrm{b}}$ \\
\hline A-1-1 & 56 & M & 3 & 1 & 0 & 3 & $\mathrm{CR}$ & $\mathrm{A}(>2171)$ \\
\hline A-1-2 & 61 & M & 3 & 1 & 1 & 4 & $\mathrm{CR}$ & $\mathrm{A}(>2233)$ \\
\hline A-1-3 & 68 & M & 3 & 1 & 0 & 3 & $\mathrm{CR}$ & $\mathrm{A}(>2012)$ \\
\hline A-1-4 & 48 & M & 3 & 0 & 0 & $2 \mathrm{~A}$ & $\mathrm{CR}$ & $\mathrm{A}(>1891)$ \\
\hline A-1-5 & 55 & M & 3 & 0 & 0 & $2 \mathrm{~A}$ & $\mathrm{CR}$ & $\mathrm{A}(>2076)$ \\
\hline A-1-6 & 54 & M & 2 & 1 & 0 & $2 \mathrm{~B}$ & $\mathrm{CR}$ & $\mathrm{A}(>1857)$ \\
\hline A-1-7 & 67 & M & 3 & 0 & 0 & $2 \mathrm{~A}$ & $\mathrm{CR}$ & $\mathrm{A}(>1901)$ \\
\hline A-1-8 & 68 & $\mathrm{M}$ & 3 & 1 & 0 & 3 & $\mathrm{CR}$ & $\mathrm{A}(>1733)$ \\
\hline A-1-9 & 50 & M & 3 & 1 & 0 & 3 & $\mathrm{CR}$ & $\mathrm{A}(>1527)$ \\
\hline A-1-10 & 65 & M & 3 & 1 & 0 & 3 & $\mathrm{CR}$ & $\mathrm{A}(>1367)$ \\
\hline A-1-11 & 72 & M & 3 & 0 & 0 & $2 \mathrm{~A}$ & $\mathrm{CR}$ & $\mathrm{A}(>1366)$ \\
\hline A-1-12 & 64 & $\mathrm{~F}$ & 3 & 1 & 0 & 3 & $\mathrm{CR}$ & $\mathrm{A}(>1346)$ \\
\hline A-1-13 & 58 & $\mathrm{~F}$ & 3 & 1 & 0 & 3 & $\mathrm{CR}$ & $\mathrm{A}(>1233)$ \\
\hline A-1-14 & 72 & M & 3 & 0 & 0 & $2 \mathrm{~A}$ & $\mathrm{CR}$ & $\mathrm{A}(>1136)$ \\
\hline D-1-1 & 72 & $\mathrm{~F}$ & 3 & 1 & 0 & 3 & Non-CR & $\mathrm{D}(379)$ \\
\hline D-1-2 & 60 & M & 3 & 1 & 0 & 3 & Non-CR & $\mathrm{D}(251)$ \\
\hline D-1-3 & 61 & M & 3 & 1 & 1 & 4 & Non-CR & $\mathrm{D}(227)$ \\
\hline D-1-4 & 49 & $\mathrm{M}$ & 3 & 1 & 1 & 4 & Non-CR & D (239) \\
\hline D-1-5 & 53 & M & 3 & 0 & 0 & $2 \mathrm{~A}$ & Non-CR & $\mathrm{D}(364)$ \\
\hline D-1-6 & 50 & M & 3 & 1 & 1 & 4 & Non-CR & $\mathrm{D}(226)$ \\
\hline D-1-7 & 55 & M & 2 & 1 & 0 & $2 \mathrm{~B}$ & Non-CR & $\mathrm{D}(280)$ \\
\hline D-1-8 & 70 & M & 3 & 0 & 1 & 4 & Non-CR & D (299) \\
\hline D-1-9 & 72 & M & 3 & 1 & 1 & 4 & Non-CR & D (156) \\
\hline D-1-10 & 75 & M & 3 & 0 & 0 & $2 \mathrm{~A}$ & Non-CR & D (309) \\
\hline D-1-11 & 67 & M & 3 & 1 & 0 & 3 & Non-CR & $\mathrm{D}(236)$ \\
\hline A-2-1 & 71 & M & 3 & 0 & 0 & $2 \mathrm{~A}$ & $\mathrm{CR}$ & $\mathrm{A}(>912)$ \\
\hline A-2-2 & 70 & M & 3 & 1 & 0 & 3 & $\mathrm{CR}$ & $\mathrm{A}(>1018)$ \\
\hline A-2-3 & 44 & $\mathrm{M}$ & 3 & 0 & 0 & $2 \mathrm{~A}$ & $\mathrm{CR}$ & $\mathrm{A}(>919)$ \\
\hline A-2-4 & 55 & $\mathrm{M}$ & 3 & 0 & 0 & $2 \mathrm{~A}$ & $\mathrm{CR}$ & $\mathrm{A}(>959)$ \\
\hline D-2-1 & 71 & M & 3 & 1 & 0 & 3 & $\mathrm{CR}$ & $\mathrm{D}(664)$ \\
\hline D-2-2 & 64 & M & 2 & 1 & 0 & $2 B$ & $\mathrm{CR}$ & D (299) \\
\hline D-2-3 & 61 & M & 3 & 1 & 0 & 3 & $\mathrm{CR}$ & $\mathrm{D}(968)$ \\
\hline D-2-4 & 59 & $\mathrm{~F}$ & 3 & 0 & 0 & $2 \mathrm{~A}$ & $\mathrm{CR}$ & $\mathrm{D}(521)$ \\
\hline
\end{tabular}

${ }^{\mathrm{a}} \mathrm{A}$ CR was defined as the complete disappearance of all measurable and assessable disease for a minimum of 4 -weeks. ${ }^{\mathrm{b}} \mathrm{Disease-free}$ survival (days).

this cluster survived for more than 2 years. In summary, 11 (79\%) of the 14 long-term survivors (A-1-1 to A-1-14) or 16 $(80 \%)$ of the 20 cases that survived for more than 2 years were grouped into clusters 1 and 3, whereas cluster 2 was characterized by a poorer prognosis, gathering $9(82 \%)$ of the 11 short-term survivors (D-1-1 to D-1-11) or 10 (77\%) of 13 cases that survived for less than 2 years. These unsupervised data on expression profiling suggested the presence of distinct subclasses within the 33 patient groups, and the subclasses may be associated with the survival term.
To compile a gene list for prognostic marker candidates for CRT, we selected genes by comparing expression levels between the two groups, 14 long-term survivors and 11 shortterm survivors. A gene was selected if more than $60 \%$ of the samples in one group expressed the gene at a higher level than an average of signal intensity plus its standard deviation (SD) in the other group. By this procedure, 57 genes associated with short-term survival and 120 genes with long-term survival were identified (Table II). To investigate whether the subclass exists among long-term survivors or short-term survivors, we 

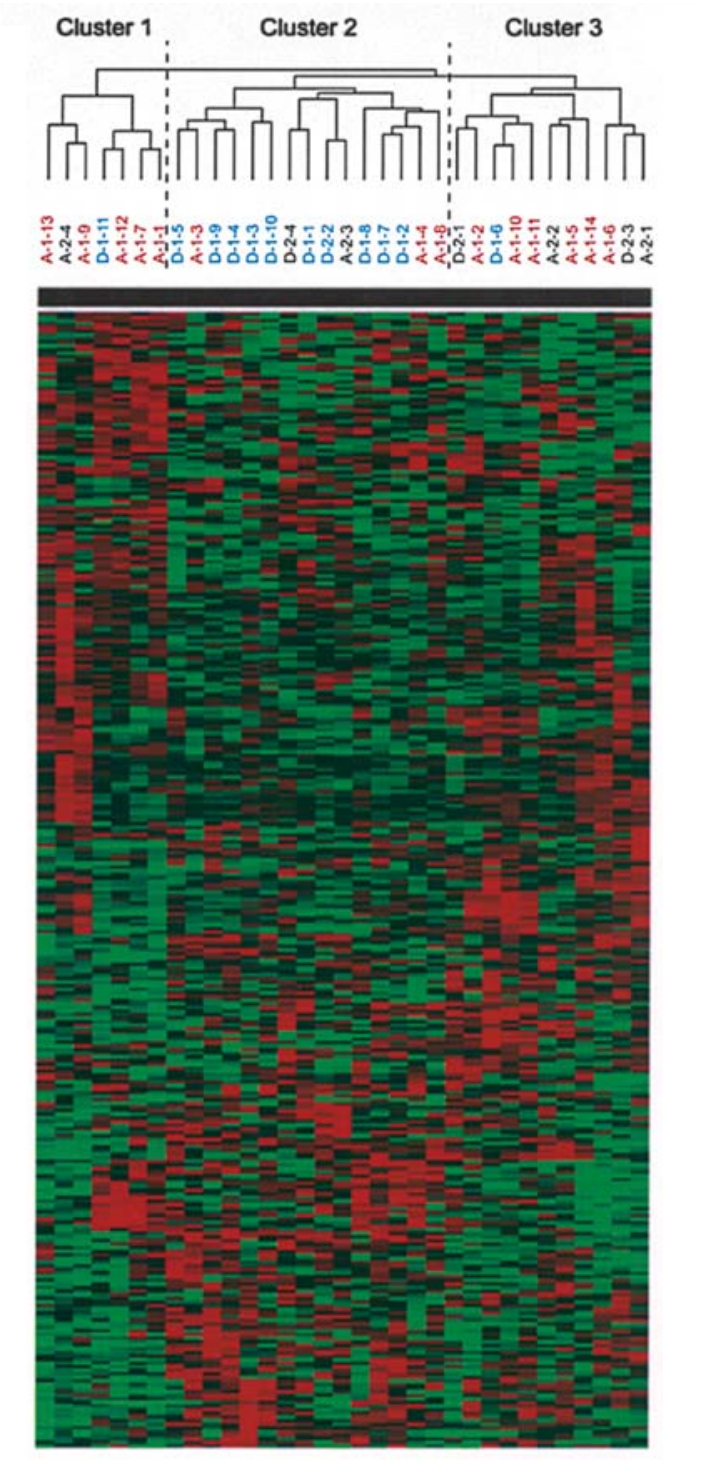

Figure 1. Unsupervised clustering analysis with expression data of the 316 genes in the 33 ESCC patients treated with CRT alone. Expression data of the 316 genes expressed in all the 33 samples were analyzed by the Cluster and Treeview programs (11). The results showed a significant association between the expression profile and the survival term. The long-term survivors (red), the short-term survivors (blue).

carried out a two-dimensional hierarchical clustering analysis of the 177 selected genes. A dendrogram of the clustering analysis was generated, and is shown in Fig. 2. Two patient clusters (vertical bar) and three gene clusters (horizontal bar) were recognized. One of the two patient clusters consisted of 10 of 11 short-term survivors, and the other patient cluster included all of the 14 long-term survivors. Only one case (D-1-11) was found in an inappropriate cluster. Among the gene clusters, the 11 short-term survivors appear to compose a single gene cluster (A in Fig. 2), whereas two major gene clusters, B and C, exist for the 14 long-term survivors.

Genes differentially expressed between long-and short-term survivors. We next analyzed the known functional annotations of 177 genes identified as differentially expressed genes between the long- and short-term survivors. More than 20 out of 120 genes over-expressed in the long-term survivors were found to have some functions in the immune response (Table II).
Table II. Over-expressed genes in long- or short-term survivors.

\begin{tabular}{|c|c|c|}
\hline No. & GenBank & Gene symbol \\
\hline \multicolumn{3}{|c|}{$\begin{array}{l}\text { Long-term } \\
\text { survivor }\end{array}$} \\
\hline 1 & U19142 & GAGE1 \\
\hline 2 & L76191 & IRAK1 \\
\hline 3 & X53777 & RPL17 \\
\hline 4 & AF023612 & DIM1 \\
\hline 5 & M96860 & DPP6 \\
\hline 6 & AF031416 & IKBKB \\
\hline 7 & Z48482 & MMP15 \\
\hline 8 & S61953 & ERBB3 \\
\hline 9 & Y18448 & BSN \\
\hline 10 & W26628 & MRPL9 \\
\hline 11 & M24194 & GNB2L1 \\
\hline 12 & D63478 & NICE-4 \\
\hline 13 & AF054187 & NACA \\
\hline 14 & U84570 & C21 orf2 \\
\hline 15 & J03592 & SLC25A6 \\
\hline 16 & U87954 & PA2G4 \\
\hline 17 & Z48481 & MMP14 \\
\hline 18 & AB016902 & MLLT4 \\
\hline 19 & AI381790 & APM2 \\
\hline 20 & M24194 & GNB2L1 \\
\hline 21 & M62982 & ALOX12 \\
\hline 22 & Y00764 & UQCRH \\
\hline 23 & X78710 & MTF1 \\
\hline 24 & H16917 & KIAA0563 \\
\hline 25 & AB028959 & KIAA1036 \\
\hline 26 & M86667 & NAP1L1 \\
\hline 27 & M32334 & ICAM2 \\
\hline 28 & L05148 & ZAP70 \\
\hline 29 & M31767 & MGMT \\
\hline 30 & M54914 & FSHB \\
\hline 31 & M60483 & PPP2CA \\
\hline 32 & M90356 & BTF3L 3 \\
\hline 33 & X96969 & SLC14A2 \\
\hline 34 & $\mathrm{Z} 50853$ & CLPP \\
\hline 35 & X75252 & PBP \\
\hline 36 & AB029036 & TRIM33 \\
\hline 37 & AB014596 & FBXW1B \\
\hline 38 & M58458 & RPS4X \\
\hline 39 & $\mathrm{Z} 25749$ & RPS7 \\
\hline 40 & AF070638 & CGI-57 \\
\hline 41 & Z46973 & PIK3C3 \\
\hline 42 & L33842 & IMPDH2 \\
\hline 43 & J04132 & CD3Z \\
\hline 44 & S72869 & D10S170 \\
\hline 45 & M31315 & $\mathrm{F} 12$ \\
\hline 46 & U70451 & MYD88 \\
\hline 47 & L19185 & PRDX2 \\
\hline 48 & D11466 & PIGA \\
\hline 49 & D89667 & MM-1 \\
\hline 50 & D21089 & XPC \\
\hline 51 & U19144 & GAGE3 \\
\hline 52 & AL050135 & RFX5 \\
\hline 53 & AB018344 & DDX46 \\
\hline 54 & AF052155 & SEC13L1 \\
\hline 55 & U19145 & GAGE5 \\
\hline 56 & X15940 & RPL31 \\
\hline 57 & AF039555 & VSNL1 \\
\hline 58 & S79522 & RPS27A \\
\hline 59 & $\mathrm{AC} 004523$ & CYP4F12 \\
\hline 60 & X78926 & ZNF268 \\
\hline
\end{tabular}


Table II. Continued.

\begin{tabular}{|c|c|c|c|c|c|}
\hline No. & GenBank & Gene symbol & No. & GenBank & Gene symbol \\
\hline $\begin{array}{l}\text { Long-term } \\
\text { survivor }\end{array}$ & & & $\begin{array}{l}\text { Short-term } \\
\text { survivor }\end{array}$ & & \\
\hline 61 & U91329 & KIF1C & 1 & AF030428 & T1A-2 \\
\hline 62 & AB002332 & CLOCK & 2 & Z80782 & HIST1H2BI \\
\hline 63 & AF054174 & H2AFY & 3 & AF035287 & SDFR1 \\
\hline 64 & Z11692 & EEF2 & 4 & Y08614 & XPO1 \\
\hline 65 & AA846749 & APOM & 5 & AL049944 & DKFZP564G2022 \\
\hline 66 & D83702 & CRY1 & 6 & Z83738 & HIST1H2BM \\
\hline 67 & $\mathrm{U} 22526$ & LSS & 7 & U35451 & CBX1 \\
\hline 68 & AB007960 & SH3GLB1 & 8 & AL050089 & BAZ1A \\
\hline 69 & $\mathrm{~J} 02625$ & CYP2E1 & 9 & AF009615 & ADAM10 \\
\hline 70 & AL080119 & PAI-RBP1 & 10 & X59892 & WARS \\
\hline 71 & M24398 & PTMS & 11 & U51920 & SRP54 \\
\hline 72 & AI816034 & NOLA2 & 12 & D13629 & KTN1 \\
\hline 73 & M32313 & SRD5A1 & 12 & Z80779 & $\begin{array}{l}\text { K IN1 } \\
\text { HIST1H2BF }\end{array}$ \\
\hline 74 & L18960 & EIF1A & 13 & AB023187 & $\begin{array}{l}\text { HIST1H2BF } \\
\text { KIAA0970 }\end{array}$ \\
\hline 75 & D87002 & IGL & 14 & АВU2318/ & KIAA0970 \\
\hline 76 & S76992 & VAV2 & 15 & U53204 & PLEC1 \\
\hline 77 & M95678 & PLCB2 & 16 & D38551 & RAD21 \\
\hline 78 & X69391 & RPL6 & 17 & AI888084 & GPR107 \\
\hline 79 & M86546 & PBX1 & 18 & X63679 & TRAM1 \\
\hline 80 & AB002533 & KPNA4 & 19 & D83485 & GRP58 \\
\hline 81 & M58378 & SYN1 & 20 & AL120559 & ARPP-19 \\
\hline 82 & X53505 & RPS12 & 21 & U29332 & FHL2 \\
\hline 83 & Y09445 & TBX5 & 22 & AF013759 & CALU \\
\hline 84 & AF112472 & CAMK2B & 23 & X82103 & COPB \\
\hline 85 & AF025654 & RNGTT & 24 & AA142964 & LOC285148 \\
\hline 86 & $\mathrm{AB} 007447$ & FLN29 & 25 & AL049851 & CARD10 \\
\hline 87 & AF006621 & SLC30A9 & 26 & U76421 & ADARB1 \\
\hline 88 & U35139 & NDN & 27 & AI365215 & RRAS2 \\
\hline 89 & M23323 & CD3E & 28 & AF084523 & CREG \\
\hline 90 & U79259 & DJ159A19.3 & 29 & M35878 & IGFBP3 \\
\hline 91 & X04828 & GNAI2 & 30 & AF085692 & ABCC 3 \\
\hline 92 & Z22865 & DPT & 31 & D38521 & PSME4 \\
\hline 93 & AF037195 & RGS14 & 32 & L02426 & PSMC1 \\
\hline 94 & W72733 & KIAA1536 & 33 & U81006 & TM9SF2 \\
\hline 95 & AL096744 & REV3L & 34 & AJ 223352 & HIST1H2BK \\
\hline 96 & $\mathrm{AB} 005047$ & SH3BP5 & 35 & AF043324 & NMT1 \\
\hline 97 & AB007896 & KIAA0436 & 36 & AB014562 & PHF2 \\
\hline 98 & L24564 & RRAD & 37 & AA 176780 & TRIM44 \\
\hline 99 & W26677 & FLJ35827 & 38 & AJ010901 & MUC4 \\
\hline 100 & $\mathrm{Z} 22555$ & SCARB1 & 39 & L04282 & ZNF148 \\
\hline 101 & M64174 & JAK1 & 40 & M57730 & EFNA1 \\
\hline 102 & U88629 & ELL2 & 41 & AF038844 & DUSP14 \\
\hline 103 & S77812 & FLT1 & 42 & AB014529 & AKAP11 \\
\hline 104 & U26455 & ATM & $\begin{array}{l}42 \\
43\end{array}$ & J03060 & GBA \\
\hline 105 & X72631 & NR1D1 & 43 & M13194 & $\begin{array}{l}\text { EBA } \\
\text { ERCC1 }\end{array}$ \\
\hline 106 & M83088 & PGM1 & 44 & & $\begin{array}{l}\text { ERCC1 } \\
\text { KDELR1 }\end{array}$ \\
\hline 107 & M28393 & PRF1 & 45 & X55885 & \\
\hline 108 & AF010242 & SYNPO & 46 & AF006010 & DD5 \\
\hline 109 & M81141 & HLA-DQB1 & 47 & AF012072 & EIF4G3 \\
\hline 110 & M17016 & GZMB & 48 & AB002357 & KIF3B \\
\hline 111 & U69645 & ZNF32 & 49 & L24123 & NFE2L1 \\
\hline 112 & X54871 & RAB5B & 50 & X76534 & GPNMB \\
\hline 113 & U15552 & HSU15552 & 51 & AF011468 & STK6 \\
\hline 114 & AB014597 & ANKRD17 & 52 & X13466 & APP \\
\hline 115 & M64322 & PTPN7 & 53 & U28249 & FXYD3 \\
\hline 116 & AB018333 & SASH1 & 54 & U49020 & MEF2A \\
\hline 117 & M98539 & PTGDS & 55 & U82328 & PDHX \\
\hline 118 & AI526079 & RPL22 & 56 & AL022162 & OCRL \\
\hline 119 & AF062341 & CTNND1 & 57 & AI018098 & MGC15523 \\
\hline 120 & AF030234 & SFRS2IP & & & \\
\hline
\end{tabular}

Table II. Continued. 
A

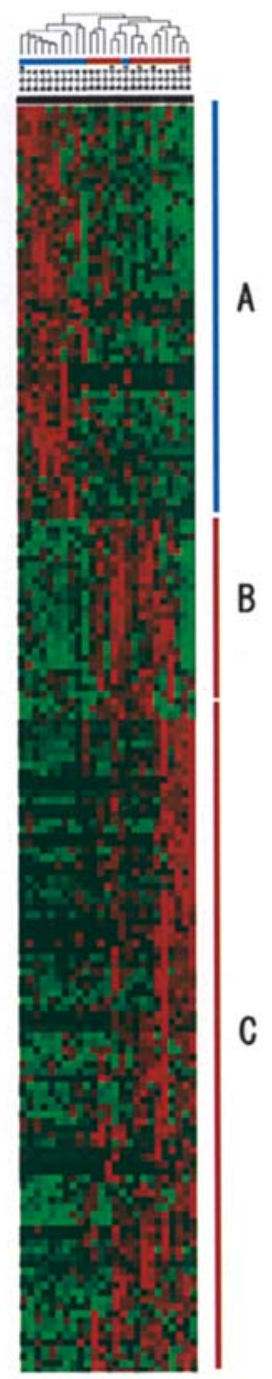

B

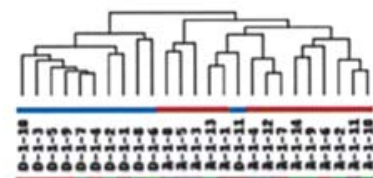

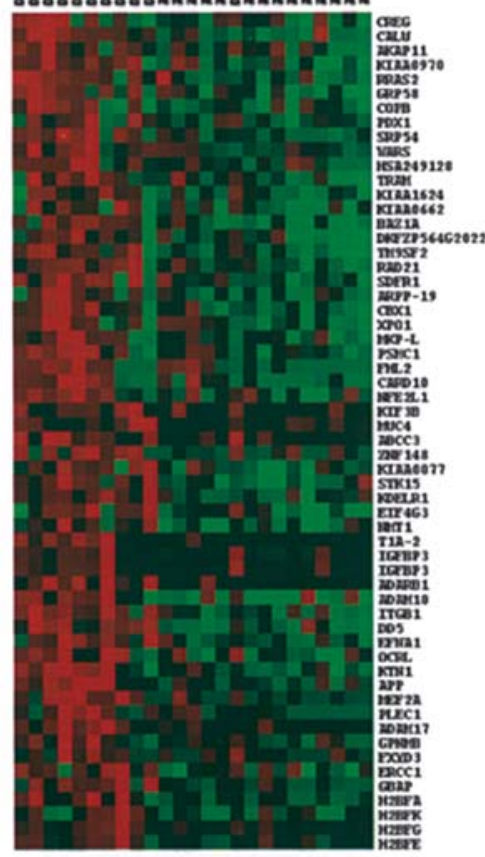

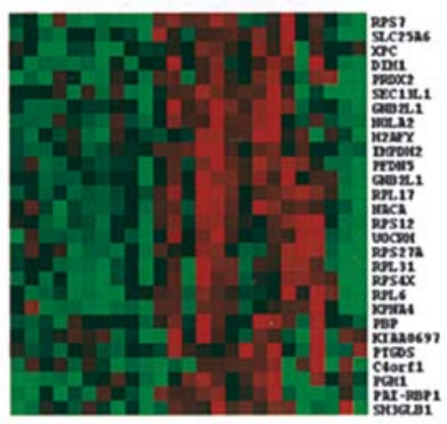

c

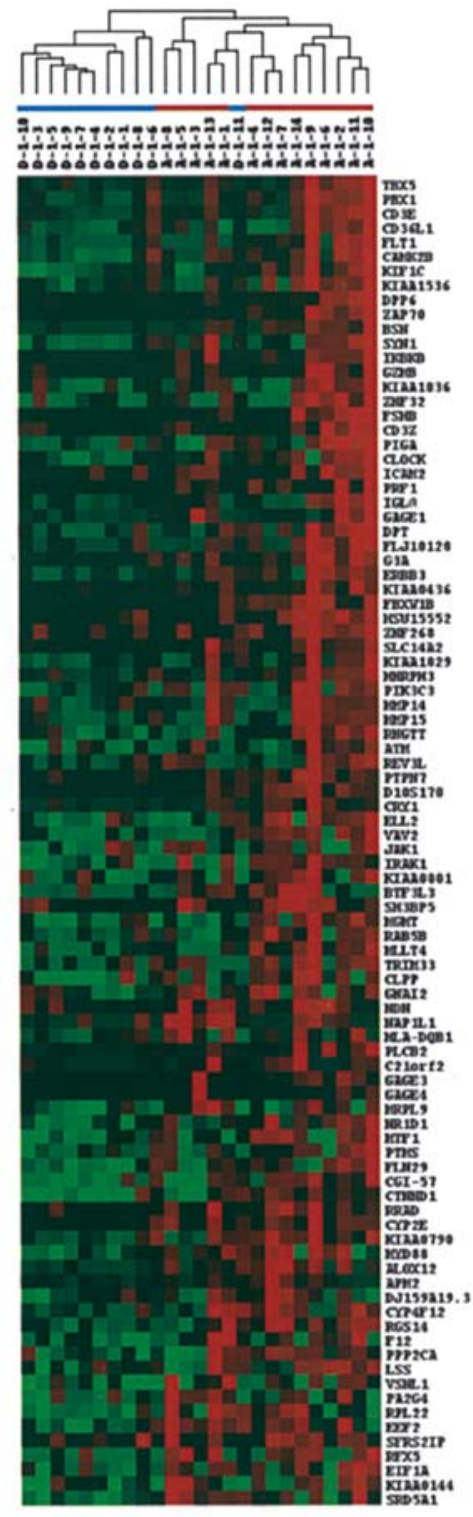

Figure 2. Supervised clustering analysis with expression data of the 177 genes differentially expressed between the 14 long-term survivors and the 11 shortterm survivors. A dendrogram of the clustering analysis was generated with the same programs as used in Fig. 1. Two patient clusters (vertical bar) and the three major gene clusters (horizontal bar) are present. Three gene clusters are indicated as an insert. The long-term survivors (red), the short-term survivors (blue).

For example, GZMB/Granzyme B, Perforin1 and ICAM2 encoding crucial effectors for cytolysis by natural killer cells and cytotoxic $\mathrm{T}$ cells or for recruitment of those cells were found over-expressed in 14,10, and 9 of the 14 long-term survivors, respectively. Similarly, of the 14 long-term survivors, upregulations were noted for GAGE1, 3 and 5 encoding tumor antigen mRNAs in 11,12 , and 10 patients, IRAKI, $M y D 88$ and $I K B K B$ encoding factors for IL-1 receptor-mediated NFKB activation in 11, 9, and 9 patients, VAV2 and ZAP70 encoding crucial effectors for T cell activation by APC-T cell interaction in 9 and 9 patients, and the MHC class II gene in 9 patients, respectively. These data suggest that cytotoxic $\mathrm{T}$ cell activation occurred preferentially in the long-term survivors. It is also noted that a vascular endothelial cell receptor gene $F L T 1$ was over-expressed in 7 of the 14 longterm survivors.
In contrast, there was only a limited number of genes involved in $\mathrm{T}$ cell activation in the 11 short-term survivors. As shown in Table II, 57 genes associated with the shortterm survivors were identified. ABCC3/MRP3 and ERCC1 which are involved in drug resistance were found overexpressed in 9 and 8 of the 11 short-term survivors. Among the other over-expressed genes in the short-term survivors, $B A Z 1 A$ and SRP54, which were located at chromosome 14q12-13, have been reported amplified in ESCCs (12).

To verify the differences in expression indicated by microarray analysis, we performed slot blot analysis of cRNAs produced from total RNA extracted from 8 of the 14 long-term survivors and 8 of the 11 short-term survivors, whose RNAs were available in both microarray and slot blot analyses. Microarray data and the slot blot data of some of the above-mentioned genes are shown in Fig. 3. By slot blot analysis, over-expression 


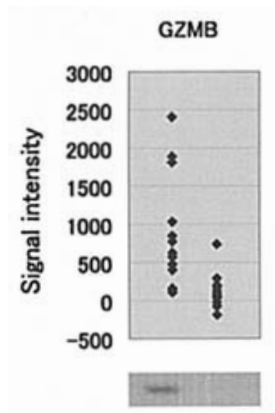

L S

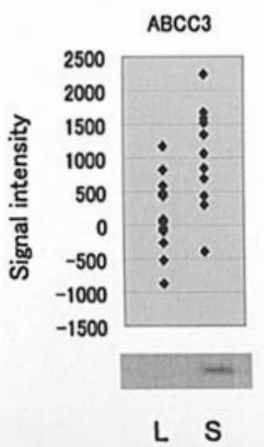

L S

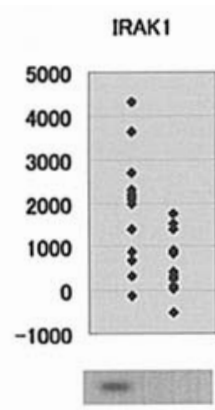

L S

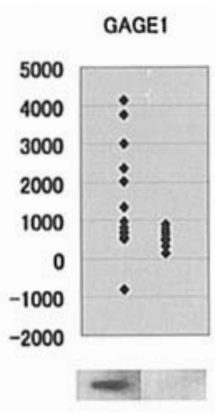

L S

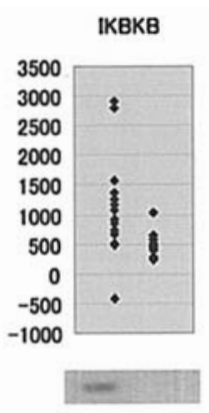

L S

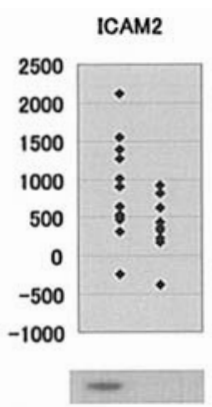

L S a

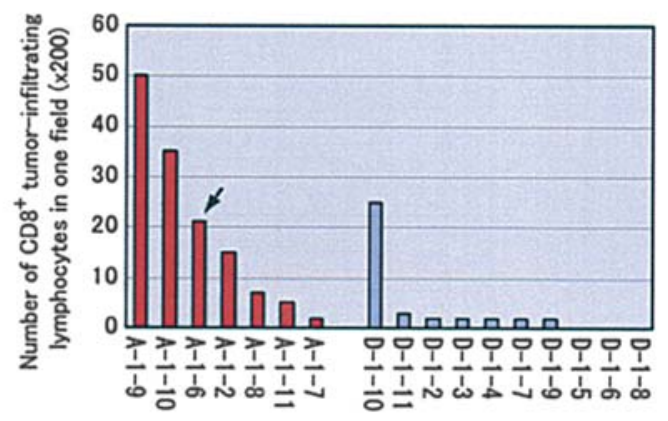

b

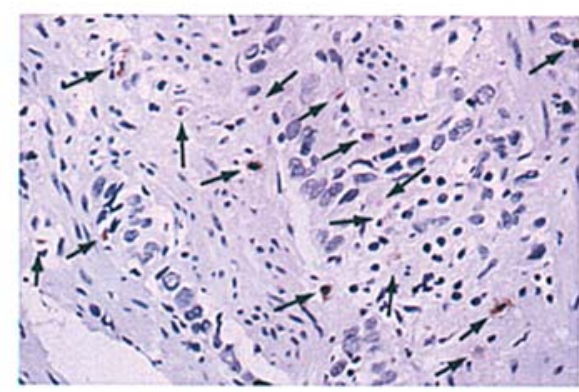

A-1-6 (x200)

Figure 4. Immunohistochemical analysis of tumor infiltrating T-lymphocytes in long- and short-term survivors. (a), The CD8-positive $\mathrm{T}$ cell number in a field (x200) in 7 long-term survivors were $50,35,21,15,7,5$ and 2 , respectively, whereas those in 11 short-term survivors were $25,3,2,2,2,2$, $2,0,0,0$, and 0 , respectively. (b), A representative result showing presence of tumor infiltrating CD8-positive T cells in long-term survivors is shown.

of $G Z M B, I C A M, G A G E 1, I R A K 1$, and IKBKB was observed in the long-term survivors. In the short-term survivors, overexpression of $A B C C 3$ and $I G F B P 3$ was confirmed.
Comparison of the number of tumor infiltrating T-lymphocytes between long- and short-term survivors. Next, using paraffinembedded tissues of 7 biopsy samples of the 14 long-term survivors and all of the 11 short-term survivors, which were available for immunohistochemistry, we compared the number of tumor infiltrating lymphocytes between the long-term survivors and the short-term survivors. As shown in Fig. 4, the CD8-positive $\mathrm{T}$ cell numbers in a field (x200) in 7 longterm survivors were $50,35,21,15,7,5$ and 2, respectively, whereas those in 11 short-term survivors were $25,3,2,2,2$, $2,2,0,0,0$, and 0 , respectively. The CD8-positive T cell number in the long-term survivors was significantly higher than that in the short-term survivors, although A-1-7 and D-1-10 were exceptions. However, D-1-10, the short-term survivor with $25 \mathrm{CD} 8$-positive $\mathrm{T}$ cells in a field, showed no over-expression of any of the 14 above-mentioned genes for $\mathrm{T}$ cell activation, whereas the genes were over-expressed in all of the long-term survivors except A-1-7. These data suggested that the increased number of activated $\mathrm{T}$ cells in a tumor is significantly associated with a good prognosis for patients with ESCC treated by CRT.

\section{Discussion}

The clustering analysis on gene expression profiles (Fig. 2) together with the known functions of the genes selected as prognostic marker candidates (Table II) suggested that multiple factors are involved in the sensitivity and resistance to CRT in ESCC. The early studies in the basic radiation biology of tumor tissues, both in vitro and in vivo showed that well-oxygenated cells are radiosensitive (13-15). Recently, it has been reported that microvessel density in laryngeal SCCs and ESCCs is a useful factor for predicting radiosensitivity $(16,17)$. These vascularity-oxygenation-radio- 
sensitivity relationships seem to be supported also by our analysis, in which we noted over-expression of a tumor vessel marker gene FLT1 in the long-term survivors.

Second, it has been recognized that doses of radiation, lower than or equal to those that cause direct cytolysis, may alter the phenotype of target tissue by up-regulating gene products that may make tumor cells more susceptible to Tcell-mediated immune attack $(18,19)$. Our present results (Fig. 4) suggest that the effect of CRT is correlated with the number of CD8-positive $\mathrm{T}$ cells in a tumor in each patient. Therefore, genes for $\mathrm{T}$ cell activation and for tumor vessel formation may become good markers for identifying potentially long-term survivors.

On the other hand, identification of poor-responders to CRT is also clinically important in the decision process for treatment modality. The genes which might be associated with the short-term survival include those for drug resistance or apoptosis resistance and some genes such as BAZ1A and SRP54 showing gene amplification in ESCC.

Establishment of a CRT response prediction algorithm requires ascertainment of another set of validation samples. However, our analysis suggests the feasibility of such class prediction, and the gene list may contribute to the understanding of the underlying molecular architecture of the heterogeneity of CRT responses and the selection of useful markers for predicting the prognosis of individual ESCC patients treated with CRT alone.

\section{Acknowledgments}

This work was supported in part by the program for promotion of Fundamental Studies in Health Sciences of the National Institute of Biomedical Innovation (NiBio), in part by a Grant-in-Aid for the Third Comprehensive 10-Year Strategy for Cancer Control and for Cancer Research (15-5 and 16-16) from the Ministry of Health, Labour and Welfare of Japan, and in part by a Research Grant of the Princess Takamatsu Cancer Research Fund. A.A. was an awardee of Research Resident Fellowships from the Foundation for Promotion of Cancer Research.

\section{References}

1. Roth JA and Putnam JB Jr: Surgery for cancer of the esophagus. Semin Oncol 21: 453-461, 1994.

2. Akiyama $\mathrm{H}$, Tsurumaru M, Udagawa $\mathrm{H}$ and Kajiyama Y: Radical lymph node dissection for cancer of the thoracic esophagus. Ann Sug 220: 364-373, 1994.

3. Baba M, Aikou T, Yoshinaga H, Natsugoe S, Fukumoto T, Shimazu H and Akazawa K: Long-term results of subtotal esophagectomy with three-field lymphadenectomy for carcinoma of the thoracic esophagus. Ann Sug 219: 310-316, 1994.
4. Ando N, Iizuka T, Kakegawa T, Isono K, Watanabe H, Ide H, Tanaka O, Shinoda M, Takiyama W, Arimori M, Ishida K and Tsugane S: A randomized trial of surgery with and without chemotherapy for localized squamous carcinoma of the thoracic esophagus: the Japan Clinical Oncology Group Study. J Thorac Cardiovasc Surg 114: 205-209, 1997.

5. Scanlon KJ, Newman YL and Priest DG: Biochemical basis for cisplatin and 5-fluorouracil synergism in human ovarian carcinoma cells. Proc Natl Acad Sci USA 83: 8923-8925, 1986.

6. Byfield JE: Combined modality infusional chemotherapy with radiation. In: Cancer Chemotherapy by Infusion. 2nd edition. Lokich JJ (ed). Percepta Press, Chicago, pp521-551, 1990.

7. Douple EB and Richmond RC: A review of interactions between platinum coordination complexes and ionizing radiation: implication for cancer therapy. In: Cisplatin: Current Status and New Developments. Prestayko AW, Crook ST and Karter SK (eds). Academic, Orlando, pp125-147, 1980.

8. Ohtsu A, Boku N, Muro K, Chin K, Muto M, Yoshida S, Satake M, Ishikura S, Ogino T, Miyata Y, Seki S, Kaneko K and Nakamura A: Definitive chemoradiotherapy for T4 and/or M1 lymph node squamous cell carcinoma of the esophagus. J Clin Oncol 17: 12915-12921, 1999.

9. Ishikura S, Nihei K, Ohtsu A, Boku N, Hironaka S, Mera K, Muto M, Ogino T and Yoshida S: Long-term toxicity after definitive chemoradiotherapy for squamous cell carcinoma of the thoracic esophagus. J Clin Oncol 21: 2697-2702, 2003.

10. Al-Sarraf M, Martz K, Herskovic A, Leichman L, Brindle JS, Vaitkevicius VK, Cooper J, Byhardt R, Davis L and Emami B: Progress report of combined chemoradiotherapy versus radiotherapy alone in patients with esophageal cancer: an intergroup study. J Clin Oncol 15: 277-284, 1997.

11. Eisen MB, Spellman PT, Brown PO and Botstein D: Cluster analysis and display of genome-wide expression patterns. Proc Natl Acad Sci USA 95: 14863-14868, 1998.

12. Yasui K, Imoto I, Fukuda Y, Pimkhaokham A, Yang ZO, Naruto T, Shimada Y, Nakamura Y and Inazawa J: Identification of target genes within an amplicon at 14q12-q13 in esophageal squamous cell carcinoma. Genes Chromosome Cancer 32: 112-118, 2001.

13. Suit HD and Suchato C: Hyperbaric oxygen and radiotherapy of a fibrosarcoma and of a squamous-cell carcinoma of $\mathrm{C} 3 \mathrm{H}$ mice. Radiology 89: 713-719, 1967.

14. Moulder JE and Rockwell S: Tumor hypoxia: its impact on cancer therapy. Cancer Metastasis Rev 5: 313-341, 1987.

15. Rockwell S and Moulder JE: Hypoxic fractions of human tumors xenografted into mice: a review. Int J Radiat Oncol Biol Physiol 19: 197-202, 1990.

16. Kamijo T, Yokose T, Hasebe T, Yonou H, Sasaki S, Hayashi R, Ebihara S, Miyahara H, Hosoi $\mathrm{H}$ and Ochiai A: Potential role of microvessel density in predicting radiosensitivity of $\mathrm{T} 1$ and T2 stage laryngeal squamous cell carcinoma treated with radiotherapy. Clin Cancer Res 6: 3159-3165, 2000.

17. Hironaga S, Hasebe T, Kamijo T, Ohtsu A, Boku N, Yoshida S, Saitoh $\mathrm{H}$ and Ochiai A: Biopsy specimen microvessel density is a useful prognostic marker in patients with $\mathrm{T}(2-4) \mathrm{M}(0)$ esophageal cancer treated with chemoradiotherapy. Clin Cancer Res 8: 124-130, 2002.

18. Chakraborty M, Abrams SI, Champhausen K, Liu K, Scott T, Coleman CN and Hodge JW: Irradiation of tumor cells upregulates Fas and enhances CTL lytic activity and CTL adoptive immunotherapy. J Immunol 170: 6338-6347, 2003.

19. Charlie TG, Claudia P, Mala C, Kwong-Yok T, Jeffrey S and James WH: Sublethal irradiation of human tumor cells modulates phenotype resulting in enhanced killing by cytotoxic T lymphocytes. Cancer Res 64: 7985-7994, 2004. 